\title{
Emergency Cesarean Section for Teenagers at Yalgado Ouedraogo Teaching Hospital (YOTH), Ouagadougou, Burkina Faso: Frequency, Indications, Maternal and Perinatal Prognosis
}

\author{
Yobi Alexis Sawadogo ${ }^{1,2^{*}}$, Boubakar Toure ${ }^{1,2}$, Sibraogo Kiemtore1,2, \\ Evelyne Komboigo-Savadogo3, Dantola Paul Kain 1,2, Issa Ouedraogo1,4, \\ Adama Ouattara ${ }^{1,2}$, Hyacinthe Zamane ${ }^{1,2}$, Ali Ouedraogo ${ }^{1}$, Blandine Thieba ${ }^{1}$ \\ ${ }^{1}$ Unity of Training and Research in Health Sciences (UFR/SDS), University Ouaga I Professor \\ Joseph KI-ZERBO, Ouagadougou, Burkina Faso \\ ${ }^{2}$ Yalgado OUEDRAOGO Teaching Hospital of Ouagadougou, Ouagadougou, Burkina Faso \\ ${ }^{3}$ Boromo District Hospital, Boromo, Burkina Faso \\ ${ }^{4}$ Teaching Hospital of Ouahigouya, Ouahigouya, Burkina Faso \\ Email: *sawalexis@yahoo.fr
}

How to cite this paper: Sawadogo, Y.A., Toure, B., Kiemtore, S., Komboigo-Savadogo, E., Kain, D.P., Ouedraogo, I., Ouattara, A., Zamane, H., Ouedraogo, A. and Thieba, B. (2018) Emergency Cesarean Section for Teenagers at Yalgado Ouedraogo Teaching Hospital (YOTH), Ouagadougou, Burkina Faso: Frequency, Indications, Maternal and Perinatal Prognosis. Open Journal of $\mathrm{Ob}$ stetrics and Gynecology, 8, 936-945. https://doi.org/10.4236/ojog.2018.811095

Received: July 25, 2018

Accepted: September 1, 2018

Published: September 4, 2018

Copyright (๑) 2018 by authors and Scientific Research Publishing Inc. This work is licensed under the Creative Commons Attribution International License (CC BY 4.0).

http://creativecommons.org/licenses/by/4.0/

\begin{abstract}
Objective: To study emergency cesarean section in teenagers with the goal of reducing morbidity and maternal-fetal mortality. Methods: This was a descriptive cross-sectional study with prospective collection of data on 248 cases collected from July 1st to December 31st, 2016. Results: The incidence of cesarean section in teenagers was $56.4 \%$. The average age was $18 \pm 0.4$ years old. The vast majority were primiparous $(92.7 \%)$. The main indications for emergency Caesarean section were: pre-eclampsia and its complications (20.2\%), acute fetal distress (18.5), pre-rupture syndrome (14.1\%) and bone dystocia $(11.7 \%)$. The maternal mortality rate was $1.6 \%$ and perinatal mortality was 134 per 1000 live births. Conclusion: The rate of caesarean section is high at Yalgado OUÉDRAOGO Teaching Hospital of Ouagadougou. Postoperative complications are sometimes serious and compromise the maternal and fetal outcome. There is a need for increased surveillance of all pregnant and recently delivered women to reduce maternal and perinatal mortality in teenagers.
\end{abstract}

\section{Keywords}

Caesarean Section, Emergency, Teenagers, Indications, Prognosis 


\section{Introduction}

Teenage motherhood is more common in developing countries where the proportion of female mothers before the age of 18 is often $25 \%-50 \%$. By contrast, in the industrialized world, early childbearing affects less than one in 10 women [1]. According to the World Health Organization, a teenager is anyone whose chronological age is between 10 and 19 years of age. In 2012, WHO estimated that nearly 16 million girls aged 15 to 19 and 2 million girls under the age of 15 give birth each year worldwide [2]. In Burkina Faso, more than 25\% of young women aged 15 to 19 had at least one pregnancy and $20 \%$ had a child. This proportion was twice as high in rural areas as in urban areas with $23 \%$ and $11 \%$, respectively [3]. According to the World Health Organization (WHO), maternal-fetal mortality is a real public health problem in the world. Indeed, every minute in the world, 380 women begin a pregnancy, 110 suffer a complication and die of a complication related to pregnancy or childbirth [4]. Currently teenage pregnancy is considered a special situation that raises medical problems [5]. These include the high number of clandestine induced abortions estimated at 3 million girls aged 15 to 19 each year, the late discovery of pregnancy, premature delivery, and high maternal and perinatal mortality. As a result, complications of pregnancy and childbirth are the second leading cause of death for girls aged 15 to 19 worldwide [6]. Also, in low- and middle-income countries, stillbirths and neonatal deaths are 50\% higher among children born to mothers under 20 than among mothers aged 20 to 29 . The younger the mother, the greater the risk for the mother-child couple. These teenage mothers are exposed to cardiovascular pathologies such as pre-eclampsia, eclampsia and bone dystocia due to the immaturity of the pelvis, thus increasing caesarean section rates in this population group [6] [7] [8]. Children of teenage mothers are more exposed to low birth weight, with long-term complications [6] [7]. Teenage pregnancy is a risky pregnancy due to physical immaturity, nutritional status, socioeconomic factors, partner abuse and emotional superposition [5] [7]. These risks may be of varying importance depending on the family, socio-economic and religious context [5].

In Burkina Faso, data on childbirth and its complications in teenagers are rare, so we propose to study emergency cesarean section in teenagers to identify different indications and to describe maternal, fetal and neonatal outcomes in the Department of Gynecology and Obstetrics at the Yalgado Ouedraogo Teaching Hospital to contribute to the reduction of maternal and perinatal morbidity and mortality.

\section{Patients and Method}

The obstetrics and gynecology department of the YOTH served us as the study framework. This was a descriptive cross-sectional study with prospective collection of data over a period of 06 months from 01 July 2016 to 31 December 2016. The study population was made up of all teenagers, having delivered by caesarean 
section in the department of obstetrics and gynecology during this period of study. We included in the study all parturient up to 19 years of age who had consented to the study having a gestational age of at least 28 weeks of amenorrhea and/or having given birth to a child whose birth weight is greater than or equal to 1000 grams and whose caesarean section was performed urgently in the Department of Obstetric Gynecology of YOTH.

The data collection was done using a questionnaire for the mother-newborn couple.

The sources of the data were

- the information obtained by the interrogation of the parturient

- medical records of operated teenagers and neonates hospitalized in neonatology

- the consultation register and the clinical examination of the parturient at the 45th postoperative day.

- the telephone calls of the patients not seen at the consultation of the 45th postoperative day.

- Examination of newborns at birth and on the 7th day

The variables studied were socio-demographic factors (age, place of residence, occupation, level of education, marital status), parity, clinical aspects (general signs, caesarean section indications, per and postoperative complications, care received, maternal and perinatal prognosis.

The study was conducted after the approval of the ethics committee. The anonymity and the confidentiality of the information collected have been respected. The data was entered and analyzed using the software Epi-info in version 7.2.

There is no conflict of interest in carrying out this work.

\section{Results}

\subsection{Epidemiology}

During this study period, we recorded 4299 deliveries, including 2191 cesarean deliveries (51\% of deliveries). There were 440 teenagers (a frequency of $10.2 \%$ ). Of these teenage mothers, 248 had an emergency caesarean section (56.4\%).

The age of the patients was between 13 and 19 years old with an average of 18 \pm 0.4 years. Patients aged 19 were 110 representing $44.4 \%$. Figure 1 shows the distribution of patients by age.

The average parity of teenagers who received caesarean section was $1.1 \pm 0.1$ with extremes of 1 and 3. Primiparous women accounted for $92.7 \%$ of the cases (229 patients) and pauciparous for $7.3 \%$ of the cases (19 patients).

In terms of occupation, housewives accounted for $61.3 \%$ of teenage girls. Table 1 shows the distribution of adolescent girls by occupation.

The place of residence of teenagers was urban in $73.7 \%$ of cases, rural areas in $8.9 \%$ of cases and semi-urban areas in $17.4 \%$ of cases.

Of these 248 teenage girls, 190 had a marital life ( $76.6 \%$ of the cases). Marriage was effective in $54.4 \%$ of teenage girls. The singles were 58 (23.4\%). 


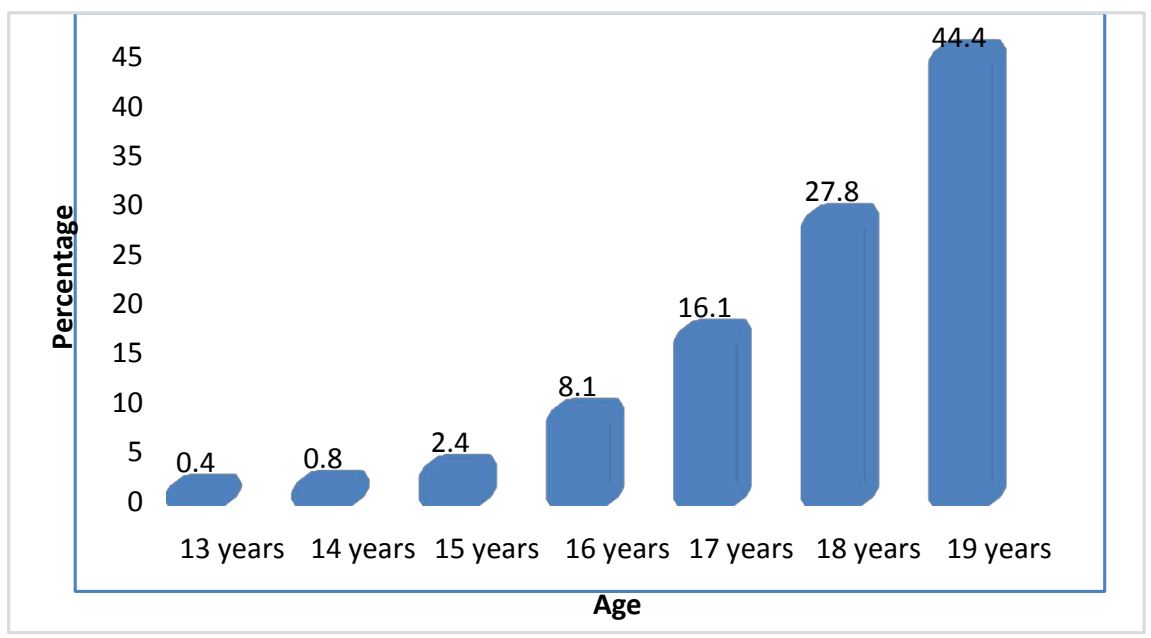

Figure 1. Distribution of teenagers by age.

Table 1. Distribution of teenagers by occupation.

\begin{tabular}{ccc}
\hline Occupation & Number & Percentage \\
\hline Housewives & 152 & 61.3 \\
Students & 63 & 25.4 \\
Informal Sector & 23 & 9.3 \\
Farmer/breeder & 6 & 2.4 \\
Employees & 4 & 1.6 \\
Total & $\mathbf{2 4 8}$ & $\mathbf{1 0 0 . 0}$ \\
\hline
\end{tabular}

Regarding the level of education, 180 patients had at least the primary level of $72.6 \%$. Table 2 shows the distribution of adolescent girls by level of education.

\subsection{Indications for Caesarean Section}

Caesarean indications are of maternal or fetal origin. Maternal indications represent $58.9 \%$ and fetal indications $41.1 \%$. Preeclampsia, acute fetal distress and pre-rupture syndrome were the main indications.

The indications for emergency cesarean sections during our study period are listed in Table 3.

\subsection{Maternal Prognosis}

In the postpartum, complications were noted in 34 patients representing $13.7 \%$ of teenage girls. The main complications were anemia and endometritis. Table 4 shows the distribution of these various complications.

The average duration of hospitalization for patients was $5 \pm 1$ day with extremes of 1 and 30 days. Figure 2 shows the distribution of teenagers by length of stay in days.

We recorded 4 maternal deaths $(1.6 \%$ of teenage girls who had a cesarean section). The causes were eclampsia ( 2 cases), pulmonary embolism (1 case) and septic shock following endometritis (1 case). 
Table 2. Distribution of teenagers by level of education.

\begin{tabular}{ccc}
\hline Education level & Number & Percentage \\
\hline Primary level & 85 & 34.3 \\
Secondary level & 89 & 35.9 \\
Higher level & 6 & 2.4 \\
Illiterate & 68 & 27.4 \\
Total & $\mathbf{2 4 8}$ & $\mathbf{1 0 0 . 0}$ \\
\hline
\end{tabular}

Table 3. Distribution of teenagers according to caesarean section indications.

\begin{tabular}{|c|c|c|}
\hline \multicolumn{3}{|c|}{ Caesarean section indications } \\
\hline Maternal Indications & Number & Percentage \\
\hline Bone dystocia & 29 & 11.7 \\
\hline Dynamic Dystocia & 10 & 4.0 \\
\hline Cervical Dystocia & 8 & 3.2 \\
\hline Eclampsia/ Pre-eclampsia & 50 & 20.2 \\
\hline Scarred uterus & 3 & 1.2 \\
\hline Pre-rupture syndrome & 35 & 14.1 \\
\hline Vaginal Diaphragm & 1 & 0.4 \\
\hline Sickle cell crisis & 6 & 2.4 \\
\hline Severe anaemia & 1 & 0.4 \\
\hline Excision's sequelae & 2 & 0.8 \\
\hline Vulvar varicose veins & 1 & 0.4 \\
\hline TOTAL (1) & 146 & 58.9 \\
\hline Fetal and adnexal Indications & Number & Percentage \\
\hline Acute fetal distress & 46 & 18.5 \\
\hline Exceeding term & 4 & 1.6 \\
\hline Beating cord prolapse & 3 & 1.2 \\
\hline Severe oligohydramnios & 1 & 0.4 \\
\hline Fetal macrosomia & 1 & 0.4 \\
\hline Vicious presentations & 31 & 12.5 \\
\hline Placenta previa & 6 & 2.4 \\
\hline Premature Rupture of membranes* & 2 & 0.8 \\
\hline Placenta abruption & 8 & 3.2 \\
\hline TOTAL 2 & 102 & 41.1 \\
\hline
\end{tabular}

*premature rupture of more than 48 hours with a bad Bishop score.

\subsection{Perinatal Prognosis}

A total of 262 newborns were registered (14 twin pregnancies) after emergency caesarean section) with 20 stillbirths. The stillbirth rate was 76 per 1000 births. 
Table 4. Distribution of teenagers by postpartum complications $(n=34)$.

\begin{tabular}{ccc}
\hline Complications & Number & Percentage \\
\hline Severe anemia & 7 & 20.6 \\
Endometritis & 7 & 20.6 \\
hemorrhage of deliverance & 3 & 12.5 \\
Hemodynamic Instability & 3 & 12.5 \\
Renal failure & 2 & 5.9 \\
Delay in postoperative wake- & 2 & 5.9 \\
fulness & 2 & 5.9 \\
Septicemia & 6 & 17.6 \\
Parietal Suppuration & 2 & 5.9 \\
Thrombophlebitis & 34 & 100.0 \\
Total & &
\end{tabular}

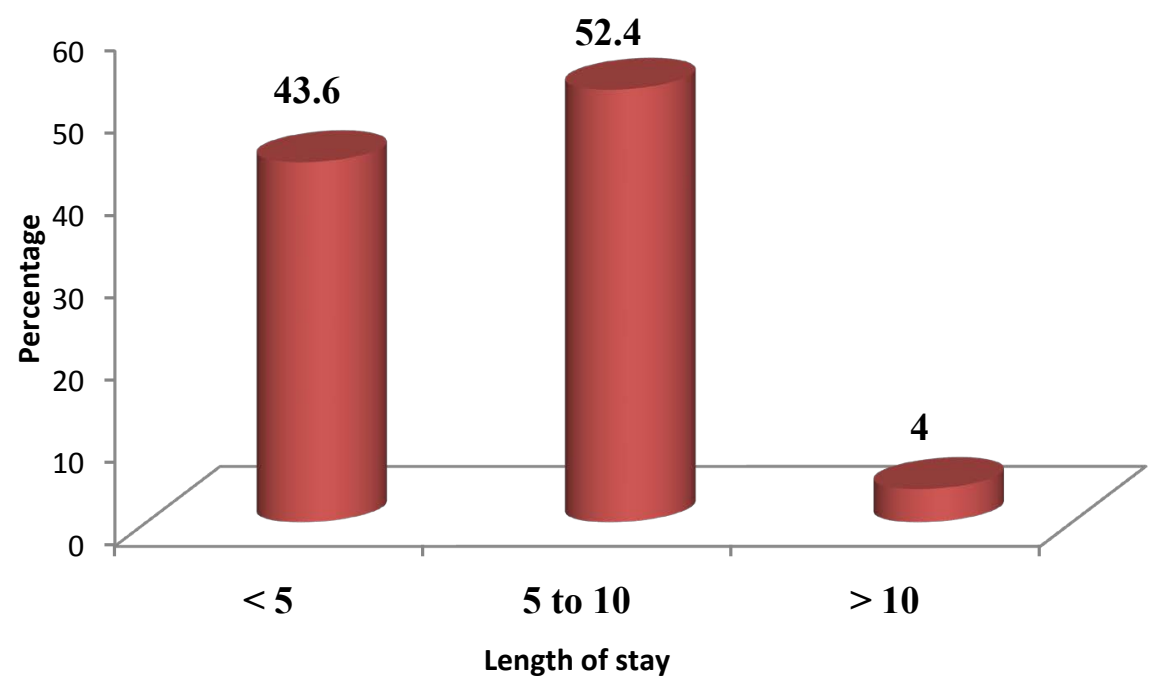

Figure 2. Distribution of patients by length of stay in days $(n=248)$.

The average weight of the newborns was $2875 \mathrm{~g} \pm 582$ with extremes of 1000 and 5150 g. Newborns with low birth weight accounted for $19.1 \%$, compared with $78.6 \%$ for normal-weight neonates and $2.3 \%$ for macrosomia.

The Apgar score in the 5th minute was less than 3 in 28 infants (10.7\%). It was between 3 and 6 in $8.3 \%$ of newborns. Of these 50 neonates not having a good Apgar score, 30 were resuscitated, representing $11.5 \%$ of all live neonates. Duration of resuscitation was 2 minutes for a newborn, 5 minutes for 20 newborns and 10 minutes for 9 newborns.

Thirty-one (31) newborns were transferred to the neonatal department, representing $12.8 \%$ of all live neonates. The transfer reasons are listed in Table 5.

In the neonatal department, we recorded 15 early neonatal deaths. The early neonatal mortality rate was 57.25 per 1000 live births. This included 7 cases of neonatal distress, 6 cases of neonatal infection and 2 cases of respiratory distress. 
Table 5. Distribution of neonates by neonatal transfer reason $(\mathrm{n}=31)$.

\begin{tabular}{ccc}
\hline Reason & Number & Percentage \\
\hline Respiratory distress & 4 & 12.9 \\
Neonatal Infection & 16 & 51.6 \\
Neonatal distress & 10 & 32.3 \\
Neonatal jaundice & 1 & 3.2 \\
Total & $\mathbf{3 1}$ & $\mathbf{1 0 0}$ \\
\hline
\end{tabular}

A total of 35 perinatal deaths were recorded representing perinatal mortality rate of 134 per 1000 live births.

\section{Discussion}

This study probably has limitations. Indeed, the age of the patients was obtained by the interrogation and by the exploitation of notebooks. The confrontation of this one with that recorded in the national identity card that has not been effective could constitute a selection bias.

Moreover, the survey card included past information (personal and family history) and patients might be mistaken in trying to remember. What could constitute an Information bias:

In our series, $56.4 \%$ of teenage girls had an emergency cesarean section. This rate is much higher than those of Hamada in Morocco and Luhete in the DRC, which were $6.1 \%$ and $11.4 \%$ [1] [2].

These high proportions could be explained by the high frequency of adolescent dystocia due not only to the immature nature of the pelvis but also to the combination of certain factors such as nutrition, pregnancy monitoring, pathologies, psychology of adolescent girls who, in the majority of cases, are not prepared to conceive.

The mean age of the patients was $18 \pm 0.4$ years. This average age is higher than that of Luhete in the DRC [2], Hamada [1] in Morocco and Iloki [6] in Congo Brazzaville, who were respectively 17.4 years, 17.3 and 14 years old.

This could be explained by difference in definition of the period of adolescence. Hamada and Iloki did not include 19-year-old girls.

The vast majority of teenage girls were primiparous. This is the same observation done in Morocco, DRC and Saudi Arabia [1] [2] [9].

In this study, housewives accounted for $61.3 \%$. The high proportion of housewives among teenage girls is consistent with most publications in Africa [10]. The low level of education of girls associated with certain socio-cultural practices (early and forced marriages) could explain this high rate of "housewives" among teenage girls.

Of the 248 parturients, 135 were married (54.4\%). In Morocco and the Democratic Republic of Congo, this proportion is greater than $80 \%$. The high proportion of married women could be explained by the persistence of early marriages 
[11]. Moreover, African habits and customs and the great monotheistic religions do not tolerate pregnancy in an unmarried girl.

The analysis of indications for emergency Cesarean section is often difficult because of the intricacy of the reasons that led to the surgical procedure. In our series, we selected those deemed major. Maternal indications ranked first with 58.9\%. Among maternal indications, preeclampsia/eclampsia was in first place with a proportion of $20.2 \%$. This result is consistent with those of the literature that young age and primiparity are recognized as risk factors for this pathology. This situation could also be explained by the fact that hypertensive pathology is clearly increasing in the developing countries where it has become a public health problem. Thus, a better lifestyle before and during pregnancy, as well as a good prenatal follow-up could help to reduce its frequency and complications.

The pre-rupture syndrome and the bony dystocia occupy 2nd and 3rd place of all indications. The proper use of the partograph, which is a tool of monitoring the childbirth labor, would allow to diagnose birth defects and to correct them in order to avoid the occurrence of pre-rupture syndrome.

This relatively high proportion of mechanical dystocia (25.8\%) could be explained in our series by the immaturity of the growing pelvis and probably the small size of teenage girls.

Fetal and adnexal indications represented $41.1 \%$. These indications were dominated by fetal distress, which accounted for $18.5 \%$ of cases. This result is similar to that found by Nelson NP in Uganda [12]. In our context, this indication is often raised in excess due to the inadequacy of the technical platform. Indeed, the diagnosis is done on the changes of the amniotic fluid color and fetal heart sounds assessed by Pinard stethoscope. Cardiotocography and measurement of fetal $\mathrm{pH}$ were not available to confirm the diagnosis.

The Postoperative recovery periods were simple for large majority of teenagers. Only $13.7 \%$ of all operated teenage girls had complications. This high rate of postoperative morbidity could be explained by late evacuations. These complications were mainly infectious despite the introduction of antibiotic prophylaxis and systematic antibiotic therapy postoperatively with ceftriaxone. Are antibiotics ineffective or unsuitable? Inadequate infection prevention and control and the three delays may also be contributing factors.

These complications caused 4 maternal deaths among operated teenagers. The maternal mortality rate was $1.6 \%$. This rate is higher than that set by WHO, which is $1 \%$, and those of Hamada in Morocco and Luhete in the DRC [1] [2].

The causes of these maternal deaths are classic: hypertensive accidents, infection and pulmonary embolism.

The prognosis of newborns is hardly better. The stillbirth rate was $7.6 \%$. This result is higher than that of Carles [13] in Guyana who found a stillbirth of 4.6\%.

These high stillbirth rates support the hypothesis that the younger the mother, the greater the risk to the child [14].

Regarding the condition of surviving infants, $18.1 \%$ of newborns had low 
birth weight. This result is similar to that of Wemaux-Dénis C in France, which found a low birth weight of $15.1 \%$ among teenagers aged $17-19$ and $19.9 \%$ among teenagers aged 13 - 15 [15]. Low birth weight is a major feature of children born to teenage mothers [14]. Low birth weight could also be explained by malnutrition and maternal anemia, which are common in developing countries.

In addition, we recorded 15 early neonatal deaths, an early neonatal mortality rate of $5.7 \%$. This rate is much higher than that of Hamada in Morocco, but it is lower than that of Luhetein the DRC [1] [2]. The lack of pediatric assistance at birth and the lack of intensive care equipment in the delivery room could be the contributing factors to this situation.

\section{Conclusions}

Emergency caesarean section is common in teenagers, and the main indications are complications of high blood pressure, mechanical dystocia and acute fetal distress.

Although this intervention saves lives, it can lead to complications that can affect maternal, fetal and neonatal prognosis. Maternal and perinatal morbidity and mortality among adolescent girls remain significant.

The improvement of maternal and fetal prognosis thus requires a strengthening of the operational capacities of the department of obstetrics and gynecology at Yalgado Teaching Hospital and health centers upstream, a real change of populations' behavior and an improvement of the system of communication also between health workers. These actions would allow for better monitoring of teenage pregnancy and delivery, and timely Caesarean section indications for early and rapid management.

\section{Conflicts of Interest}

The authors declare no conflicts of interest regarding the publication of this paper.

\section{References}

[1] Hamada, H., Zaki, A., Nejjar, H., Filali, A., Chraibi, C., Bezad, A. and Taher Tlaoui, M. (2004) Teenage Pregnancy and Delivery: Characteristics and Profile. Journal de Gynécologie Obstétrique et Biologie de la Reproduction, 33, 607-614.

[2] Luhete, P.K., Mukuku, O., Tambwe, A.M. and Kayamba, P.K.M. (2017) Study of the Maternal and Perinatal Prognosis during Childbirth in Lubumbashi, Democratic Republic of Congo. Pan African Medical Journal, 26, 182.

[3] Guiella, G. (2004) Sexual and Reproductive Health of Young People in Burkina Faso: An Inventory, Occasional Report, New York. https://www.researchgate.net/publication/237230570_Sante_Sexuelle_et_de_la_Rep roduction_des_Jeunes_au_Burkina_Faso_Un_Etat_des_Lieux

[4] Ouattara, A., Ouédraogo, C.M., Ouédraogo, A. and Lankoandé, J. (2015) References and Evacuations in Obstetrics in the Context of Emergency Obstetric and Neonatal Care Grant at CHUYO. Medicine and Tropical Health, 25, 403-407. 
[5] Soula, O., Carles, G., Largeaud, M., Guindi, W.E. and Montoya, Y. (2006) 15-19 Years Old Teenage Pregnancy and Delivery. Journal de Gynécologie Obstétrique et Biologie de la Reproduction, 35, 53-61. https://doi.org/10.1016/S0368-2315(06)76372-4

[6] Iloki, L.H., Koubaka, R. and Itoua, C. (2004) Teenage Pregnancy and Delivery in Congo about 276 Cases at Brazzaville Teaching Hospital. Journal de Gynécologie Obstétrique et Biologie de la Reproduction, 33, 37-42.

https://doi.org/10.1016/S0368-2315(04)96310-7

[7] Parra-Pingel, P.E., Guisiguina-Avellan, L.A., Hidalgo, L.C. and Perz-Lopez, F.R. (2017) Pregnancy Outcome in Younger and Older Adolescent Mothers with Severe Preeclampsia. Adolescent Health, Medicine and Therapeutics, 8, 81-86. https://doi.org/10.2147/AHMT.S131050

[8] Costa Velosso, R.M., Lopez, D.P., Vitral Pinto, I., Vidotti, C.C.F., Barufaldi, L.A., et al. (2017) Rape and Pregnancy of Girls Aged up to 13 Years in Brazil: Characteristics and Implications in Health during Gestation, Delivery and Childbirth. Ciencia \& Saude Coletiva, 22, 2909-2918.

[9] Fayed, A.A., Wahabi, H., Mamdouh, H., Koyb, R. and Esmaeil, S. (2017) Demographic Profile and Pregnancy Outcomes of Adolescents and Older Mothers in Saudi Arabia: Analysis from Riyadh Mother and Baby Cohort Study. BMJ Open, 7, e016501. https://doi.org/10.1136/bmjopen-2017-016501

[10] Ba, M.G., Sangaré, M., Moreira, P. and Diadiou, F. (1999) Practical Knowledge and Perspective of Teen Contraception. Black African Medicine, 46, 300-302.

[11] OMS: Early Marriage among Adolescents and Young Women Secretariat Report $1^{\text {st }}$ December 2008: 185. http://apps.who.int/gb/ebwha/pdf_files/WHA65/A65_13-en.pdf

[12] Nelson, J.P. (2017) Indications and Appropriateness of Ceasarean Sections Performed in a Tertiary Referral Centre in Uganda. A Retrospective Descriptive Study. The Pan African Medical Journal, 26, 64. https://doi.org/10.11604/pamj.2017.26.64.9555

[13] Carles, G., Jacquelin, X. and Raynal, P. (1998) Pregnancy and Childbirth of Adolescents under 16: Study of 150 Cases in French Guiana. Journal de Gynécologie Obstétrique et Biologie de la Reproduction, 27, 508-513.

[14] Detecker, F., De Bailliencourt, D., Barau, G., Fortier, D., Robillart, P.Y., Rogewolter, M.M., Djemili, S. and Gerardin, P. (2005) Study of Obstetric Risk Factors in the Follow-Up of 365 Pregnancies of Teenage Primiparous Women on the Island of Reunion. Journal de Gynécologie Obstétrique et Biologie de la Reproduction, 34, 694-701.

[15] Wemaux-Denis, C., Garabedian, C., Huc, A., Cailleret, O., Depoortere, M.H., Hammou, Y. and Subtil, D. (2017) Pregnancy and Delivery of Teenagers: Is Obstetrical Prognosis Worst between 13-15 Years Old? Gynécologie Obstétrique Fertilité \& Sénologie, 45, 5-8. 